\title{
Experimental research regarding the study of surface quality of aluminum alloys processed through milling
}

\author{
Alina Bianca Pop ${ }^{1}$, and Mihail Aurel Țîțu ${ }^{2, *}$ \\ ${ }^{1}$ SC TechnoCAD SA, Vasile Alecsandri no. 72, code 430351, Baia Mare, România \\ ${ }^{2}$ Lucian Blaga University of Sibiu, Victoriei Street no. 10, code 550024, Sibiu, România
}

\begin{abstract}
The aim of this paper is to present the necessary steps to conduct a design of experiment with application on the aluminum alloy surface quality obtained by end-milling process. The machined surface quality is influenced by the cutting process parameters, and especially by their variation. The research methods used in this paper are the Taguchi method to determine the cutting parameters influence, on the surface quality, and the full factorial design of experiment to confirm the results obtained by Taguchi's method and to determine the percentage of the parameters influence involved in the process.
\end{abstract}

\section{Introduction}

The cutting process is the one of the most common processing techniques in the industry. There are a multitude of studies that are investigating it, both on the industrial side and also on the academic one.

In the end milling process on the workpiece a considerable number of factors are acting, like: the material microstructure, the parameters of the cutting tool geometry, the cutting regime or the tool wear etc. Due to this fact, to obtain a high surface quality, it is necessary to study the influence degree of the mentioned factors and also, to find the optimum methods to fulfill the intended purpose.

The experimental research involves the organization of a process or phenomenon under some well-established conditions, eliminating as much as it is possible the disturbance influences.

The overall objective is to make some measurements in order to determine the value or the intensity of physical measure of the considered phenomenon or process.

With this measurements can be deduced some connections between the factors and the laws that govern the phenomenon.

The research results, the cost and the research program duration, are depending on the methods choosing, on the investigation techniques, on the experimental stages organization and also on the results processing [1].

\footnotetext{
* Corresponding author: mihail.titu@ulbsibiu.ro
} 
The purpose of this paper is to present the necessary steps of the design of experiments to study the influence exerted by the cutting process parameters on the surface quality machined by end milling of aluminum alloys, in this case the A17136 alloy.

Similar research conducted on the design of experiments were carried out by [2] who determined the process parameters influence exerted on the impact forces, using the full factorial method.

Among the previous research are the investigation of the effect of the feed rate on the surface roughness and the reduction of processing time [3], and also the mathematical modeling of a regression equation of the surface roughness obtained by end milling [4].

\section{Experimental Research Management}

To conduct an experimental research, Montgomery recommends to follow the steps mentioned [5]:

- The recognition of the problem statement;

- The response variable selection;

- The choice of the factors (process parameters), levels, and ranges;

- The choice of the experimental design;

- The experiment performing;

- The statistical data analysis;

- Conclusions and recommendations.

\subsection{The recognition of the problem statement}

After the bibliography field completing, the research problem can be formulated as follows: „The study of the arithmetic mean deviation $\mathrm{R}_{\mathrm{a}}$ of the surface profile, resulted by end milling process of the 7136 aluminum alloy, depending on the cutting process parameters."

\subsection{The response variable selection}

On this step, the response to analyze is established: the arithmetic mean deviation $\mathrm{R}_{\mathrm{a}}$ of the surface profile.

\subsection{The choice of the factors (process parameters) involved in the process}

Considering the paper purpose, the factors to study are:

- Cutting speed (v [m/min]);

- Cutting depth $\left(\mathrm{a}_{\mathrm{p}}[\mathrm{mm}]\right)$;

- Feed per tooth $\left(\mathrm{f}_{\mathrm{z}}[\mathrm{mm} /\right.$ tooth $\left.]\right)$.

Table 1. The established values of the cutting process parameters

\begin{tabular}{|c|c|}
\hline \multirow{6}{*}{ Cutting regime } & Cutting speed [m/min] \\
\hline & $\begin{array}{llllll}495 & 530 & 570 & 610 & 660 & 710\end{array}$ \\
\hline & Cutting depth [mm] \\
\hline & $\begin{array}{llllllllll}2 & 2.5 & 3 & 3.5 & 4 & 4.5 & 5 & 5.5 & 6\end{array}$ \\
\hline & Feed per tooth [mm/tooth] \\
\hline & $\begin{array}{lllll}0.04 & 0.06 & 0.08 & 0.11 & 0.14 \\
\end{array}$ \\
\hline
\end{tabular}

The choice of levels for each machining parameter was made in accordance with the SECO Tools manufacturer indications and also according to the technological possibilities of the tool, cutting inserts and CNC machine. 
These factors are exerting their influence on the analyzed response, and their settled values to performing the experiments are shown in Table 1.

\subsection{The choice of the experimental design}

The experiment type to conduct the research is the full factorial design. With the established cutting parameters and their settled levels, a number of $5 \times 6 \times 5=150$ experiments, are resulting.

After the experiments performing, the measurements will be collected.

The total number of $R_{a}$ measurements results by the each replicated experiment. In order to conduct a data statistical analysis, each experiment requires a number of 3 to 7 replications $[5]$.

In this research, the statistical analysis will be performed based on 7 measurements, made for each experiment. It follows a number of $150 \times 7=1050$ required measurements.

Based on the aspects mentioned above, first the Taguchi method shall be used to determine the influence levels of each parameter involved in the studied process (screening).

Starting with the process parameters values indicated in table 1 (settled based on the technological possibilities of the tool and of the cutting inserts), to conduct the research based on a complete factorial experiment, to use the Taguchi method it will be consider just 2 levels (the minimum and the maximum values) of each control factor, as it is shown in table 2.

Table 2. The control factors and their settled levels

\begin{tabular}{|c|c|c|c|c|}
\hline Abbreviation & \multicolumn{2}{|c|}{ Parameter } & $\begin{array}{c}\text { Value 1 } \\
\text { minimum }\end{array}$ & $\begin{array}{c}\text { Value 2 } \\
\text { maximum }\end{array}$ \\
\hline $\mathrm{A}$ & 1 & Cutting speed & $\mathrm{A} 1=495,00[\mathrm{~m} / \mathrm{min}]$ & $\mathrm{A} 2=660,00[\mathrm{~m} / \mathrm{min}]$ \\
\hline $\mathrm{B}$ & 2 & Cutting depth & $\mathrm{B} 1=2[\mathrm{~mm}]$ & $\mathrm{B} 2=4[\mathrm{~mm}]$ \\
\hline $\mathrm{C}$ & 3 & Feed per tooth & $\mathrm{C} 1=0,04[\mathrm{~mm} /$ tooth $]$ & $\mathrm{C} 2=0,14[\mathrm{~mm} / \mathrm{tooth}]$ \\
\hline
\end{tabular}

The cutting depth values were chosen according to the limiting values of the CNC machine, whose technological possibilities are limited to a maximum rotational speed of $15.000 \mathrm{rev} / \mathrm{min}$, with a safety rotational speed of $13.500 \mathrm{rev} / \mathrm{min}$ and the limiting safety on cutting depth of $4 \mathrm{~mm}$.

Further, based on the results from Taguchi method, the full factorial design will be used in order to obtain the percentage influence of each studied parameter on the surface roughness.

\subsection{The experiment performing}

The effective experiments begun with the study of 7136 aluminum alloy behavior, according to the proposed objectives under the variation of the cutting regime parameters.

The experiment was performed using a standard set of tools for aluminums machining $16 \mathrm{~mm}$ End milling cutter milling with 100\% tool engagement - SECO R217.69-1616.0-092AN, holding two indexable cutting inserts XOEX090308FR-E05, H15.

The machine used for the milling tests is a HAAS VF2 CNC.

The optical microscope Micro-Vu VERTEX 310, was used to make an optical determination and evaluation of the finished surface.

To analyze the surface roughness for different machining conditions, it was used the portable surface roughness tester - Mitutoyo SURFTEST SJ-210, with a resolution of 0.002 $\mu \mathrm{m}$. 


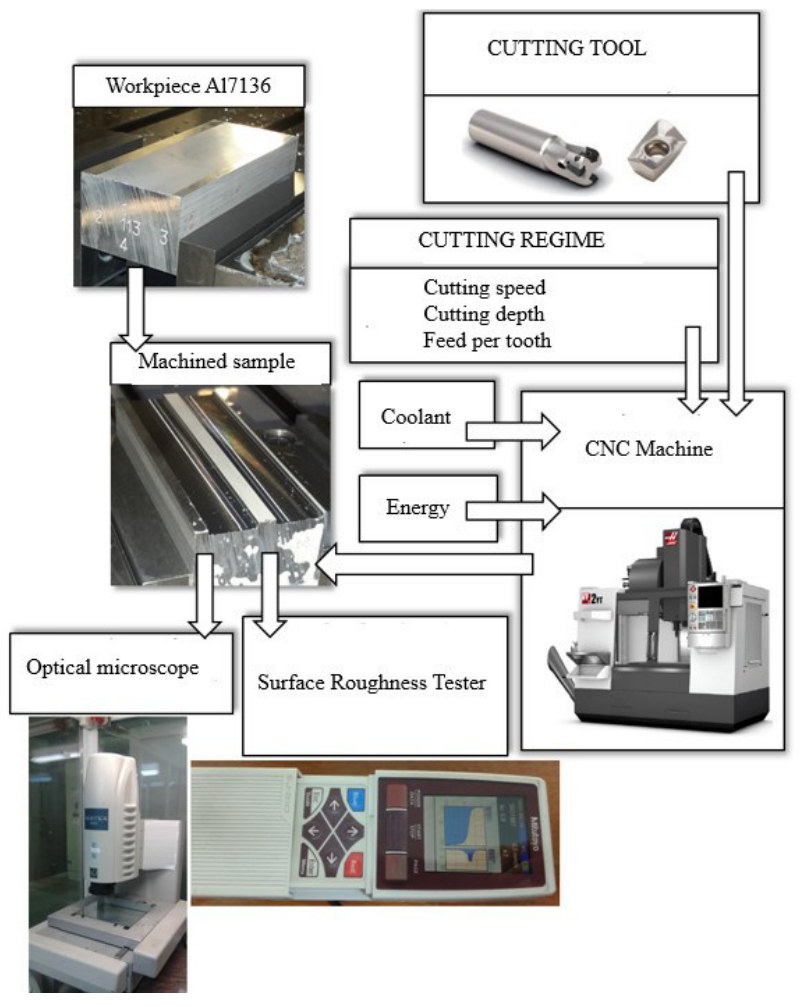

Fig. 1. Experimental stand [6]

With this experimental stand, can be fulfilled the main necessary requirements to achieve the sets objectives and also to obtain the experimental data on which can be analyzed the cutting parameters influence (cutting speed, cutting depth and feed per tooth) exerted on the machined surface roughness (fig. 1).

In the first phase, based on the Taguchi's method, data presented in table 2 will be used and a number of 8 experiments will be perform and for each experiment a set of 3 measurements will be associated, thus aiming to reduce the measurement error (Table 3).

Table 3. The values of 8 experimental setup with the measured roughness Ra values

\begin{tabular}{|c|c|c|c|c|c|c|c|}
\hline \multirow{2}{*}{$\begin{array}{c}\text { No. } \\
\text { exp. }\end{array}$} & \multicolumn{3}{|c|}{ Control factors } & \multicolumn{3}{c|}{ Surface roughness results Ra[ $\boldsymbol{\mu m}]$} \\
\cline { 2 - 8 } & $\begin{array}{c}\mathbf{v} \\
{[\mathbf{m} / \mathbf{m i n}]}\end{array}$ & $\begin{array}{c}\mathbf{a}_{\mathbf{p}} \\
{[\mathbf{m m}]}\end{array}$ & $\begin{array}{c}\mathbf{f}_{\mathbf{z}} \\
{[\mathbf{m m} / \mathbf{t o o t h}]}\end{array}$ & $\mathbf{R}_{\mathbf{a} 1}$ & $\mathbf{R}_{\mathbf{a} 2}$ & $\mathbf{R}_{\mathbf{a} 3}$ & $\mathbf{R}_{\mathbf{a m e d}}$ \\
\hline 1 & 495 & 2 & 0,04 & 0,083 & 0,063 & 0,063 & 0,070 \\
\hline 2 & 495 & 2 & 0,14 & 0,173 & 0,168 & 0,124 & 0,155 \\
\hline 3 & 660 & 4 & 0,04 & 0,44 & 0,341 & 0,456 & 0,412 \\
\hline 4 & 660 & 4 & 0,14 & 0,115 & 0,11 & 0,098 & 0,108 \\
\hline 5 & 495 & 4 & 0,04 & 0,073 & 0,064 & 0,075 & 0,071 \\
\hline 6 & 495 & 4 & 0,14 & 0,394 & 0,385 & 0,247 & 0,342 \\
\hline 7 & 660 & 2 & 0,04 & 0,079 & 0,055 & 0,088 & 0,074 \\
\hline 8 & 660 & 2 & 0,14 & 0,12 & 0,095 & 0,181 & 0,132 \\
\hline
\end{tabular}

For a better understanding of the roughness resulted values it was used the arithmetic average method. 
Given the pursued aim - to determining the factors levels to optimize the minimized quality criteria (as the roughness is lower it is better), after the Taguchi's method applying it was determined the configuration that consists of the most favorable factors levels to optimize the quality criteria: A2 B1 C1 A1B1 A1C2 B1C1.

Further, in order to determine the influence percentages of the cutting parameters involved in the process the full factorial experiment was used. In this situation, the input data consist of all cutting parameters values shown in Table 2 .

A number of $6 \times 5 \times 5=150$ experiments were carried out, which were 7 times replicated and a total of $150 \times 7=1050$ measurements was carried out.

Given these aspects, the percentages of the cutting process parameters influence exerted on the surface roughness were determined (Table 4).

The table 4 results shows that the cutting speed has the greatest influence on the surface quality obtained by end milling.

Table 4. The percentage influence of the process parameters exerted on the surface roughness [4]

\begin{tabular}{|c|c|c|c|}
\hline Source & Freedom degrees & Square sum & Percentage contribution \\
\hline Regression model & 7 & 199,482 & $86,12 \%$ \\
\hline Cutting speed A & 1 & 194,322 & $83,89 \%$ \\
\hline Cutting depth B & 1 & 0,040 & $0,02 \%$ \\
\hline Feed per tooth C & 1 & 1,157 & $0,50 \%$ \\
\hline A x B & 1 & 3,093 & $1,34 \%$ \\
\hline A x C & 1 & 0,316 & $0,16 \%$ \\
\hline B x C & 1 & 0,366 & $0,14 \%$ \\
\hline A x B x C & 1 & 0,188 & $0,08 \%$ \\
\hline Error & 827 & 32,156 & $13,88 \%$ \\
\hline Fitting error & 143 & 18,735 & $8,09 \%$ \\
\hline Pure error & 684 & 13,421 & $5,79 \%$ \\
\hline Total & 834 & 231,638 & $100 \%$ \\
\hline
\end{tabular}

\subsection{The statistical data analysis}

The statistical data analysis has a great impact on the experimental research, because can certified that the studied process values are real and they are not affected by the system errors or measurement errors.

The statistical analysis of the experimental data consists of:

1) Verifying the aleatory data character;

2) Verifying the normality distribution of the experimental data;

3) Identifying the affected data by aberrant errors.

After performing the statistical data analysis, the experimental data modelling can be carried out in order to obtain those mathematical models which are best describing the studied process.

With the $\mathrm{R}_{\mathrm{a}}$ measurements of the established experimental domain, a regression equation can be determined, which describe the surface roughness obtained by end-milling according to the involved process parameters values. 


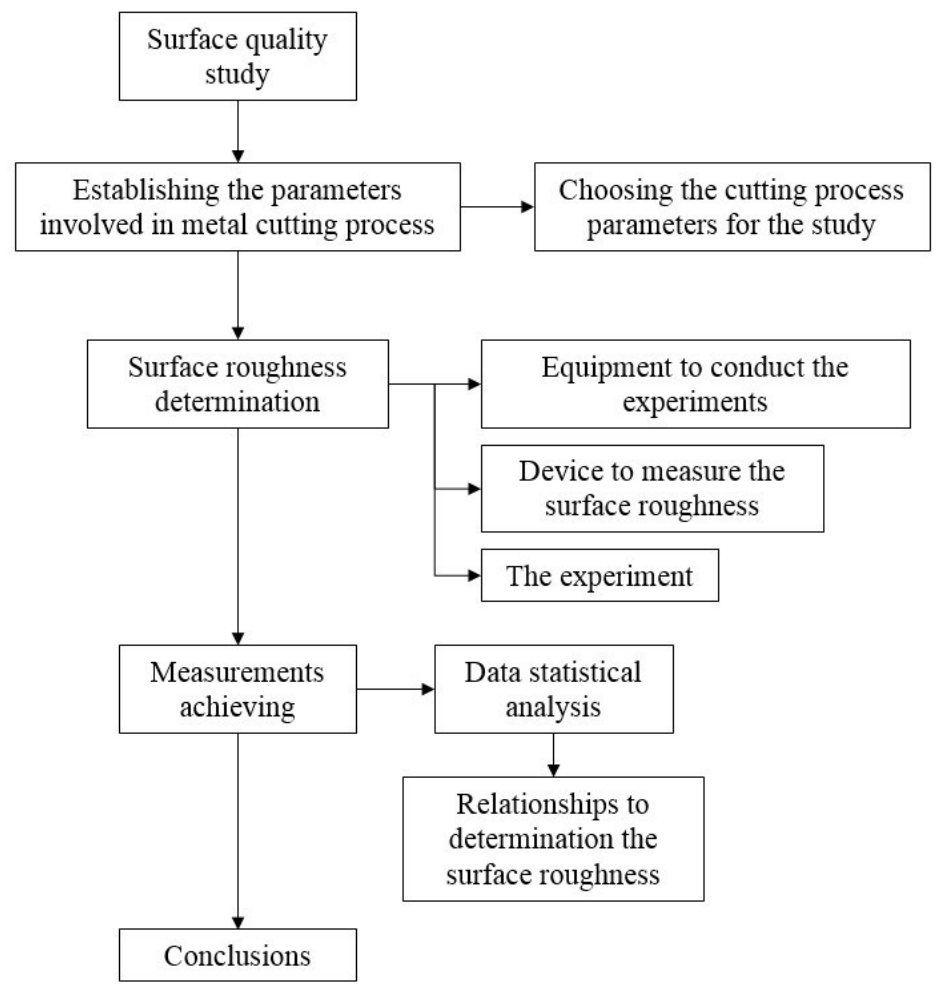

Fig. 2. Chart stages planned in the design of experiment to study the surface roughness.

In figure 2 is presented the planned stages of the design of experiment to study the surface roughness.

\section{Conclusions and recommendations}

To carry out the experimental research, it is necessary to follow a series of steps, broadly presented in scientific literature. The experimental research aim, is to improve the studied process with the preliminary obtained results.

The surface roughness is depending on certain process parameters, specifically on the cutting speed.

In the first phase three process parameters were determined: cutting speed, feed per tooth and cutting depth.

For the established experimental domain a number of 150 experiments it was necessary to carried out. In order to achieve the statistical data analysis of the experimental results obtained for each experiment, seven measurements were made; a number of 1050 measurements was resulted.

To determine the influence levels of cutting parameters was used the Taguchi's method. Then, to determine the influence values of the cutting parameters on the surface roughness was used the full factorial design.

So, using Taguchi's method for the process screening, the number of necessary experiments decreased from 150 to 8 experiments, on this way savings time and money. The statistical data analysis of the obtained results represent an important part of the design of experiment, after which the necessary steps to obtain a regression equation can be made. 


\section{References}

1. V., Năsui, A., Coteţiu, R., Coteţiu, M., Lobonţiu, N., Ungureanu, Bazele cercetării experimentale a actuatorilor electromecanici (Editura Universităţii de Nord, Baia Mare, 2007)

2. N., Medan, M., Lobonțiu, M., Bănică, MATEC Web of Conferences 94, (2017)

3. A.B. Bonţiu Pop, SCIENTIFIC BULLETIN, Serie C, Fascicle: Mechanics, Tribology, Machine Manufacturing Technology, XXVIII, 12-17 (2014)

4. A. B. Pop, M. A. Țîțu, IOP Publishing, IOP Conf. Series: Materials Science and Engineering 161 (2016)

5. D., Montgomery, Design and Analysis of Experiments (Eighth Edition ed. Hoboken: John Wiley \& Sons, Inc, 2013)

6. A. B., Bonțiu Pop, Calitatea suprafețelor la așchierea aliajelor de aluminiu cu freze cilindrofrontale, (Teza de doctorat, Baia Mare, 2015) 